BRAZZILIAN JOURNAL

OF MEDICAL AND BIOLOGICAL RESFARCH

www.bjournal.com.br
ISSN 0100-879X

Volume 44 (11) 1070-1193 November 2011

BIOMEDICAL SCIENCES

AND

CLINICAL INVESTIGATION

Braz J Med Biol Res, November 2011, Volume 44(11) 1134-1140

doi: 10.1590/S0100-879X2011007500140

Effect of TNF- $\alpha$ production inhibitors on the production of pro-inflammatory cytokines by peripheral blood mononuclear cells from HTLV-1-infected individuals

T. Luna, S.B. Santos, M. Nascimento, M.A.F. Porto, A.L. Muniz, E.M. Carvalho and A.R. Jesus

The Brazilian Journal of Medical and Biological Research is partially financed by

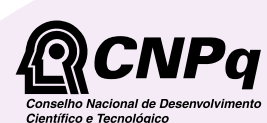

da Ciência e Tecnologia

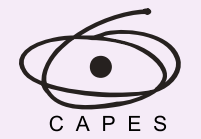

Ministério da Educação
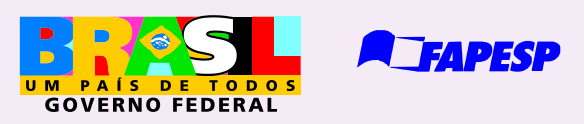

Institutional Sponsors
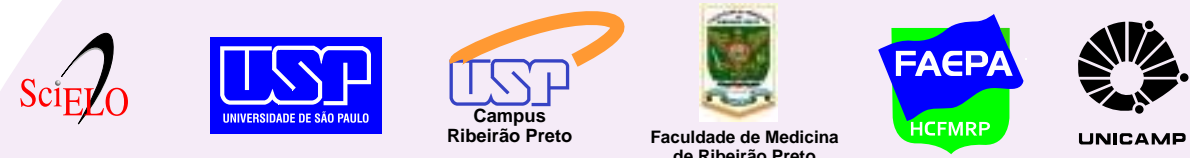

UNICAMP

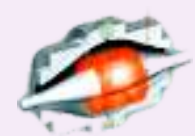

SHIMADZU

Explore High - Performance MS Orbitrap Technology In Proteomics \& Metabolomics

analitica Thermo 


\title{
Effect of TNF- $\alpha$ production inhibitors on the production of pro-inflammatory cytokines by peripheral blood mononuclear cells from HTLV-1-infected individuals
}

\author{
T. Luna1 ${ }^{1}$, S.B. Santos ${ }^{1}$, M. Nascimento ${ }^{1}$, M.A.F. Porto², A.L. Muniz¹, \\ E.M. Carvalho ${ }^{1,3}$ and A.R. Jesus ${ }^{2}$ \\ ${ }^{1}$ Serviço de Imunologia, Complexo Hospitalar Universitário Professor Edgard Santos, \\ Universidade Federal da Bahia, Salvador, BA, Brasil \\ 2Universidade Federal de Sergipe, Aracaju, SE, Brasil \\ 3 Instituto Nacional de Ciência e Tecnologia de Doenças Tropicais, Salvador, BA, Brasil
}

\begin{abstract}
Human T lymphotropic virus type 1 (HTLV-1) is the causal agent of myelopathy/tropical spastic paraparesis (HAM/TSP), a disease mediated by the immune response. HTLV-1 induces a spontaneous proliferation and production of pro-inflammatory cytokines by T cells, and increasing interferon- $\mathrm{Y}$ (IFN- $-\mathrm{Y}$ ) and tumor necrosis factor- $\alpha$ (TNF- $\alpha$ ) levels are potentially involved in tissue damage in diseases related to HTLV-1. This exaggerated immune response is also due to an inability of the natural regulatory mechanisms to down-modulate the immune response in this group of patients. TNF- $\alpha$ inhibitors reduce inflammation and have been shown to improve chronic inflammatory diseases in clinical trials. The aim of this study was to evaluate the ability of pentoxifylline, forskolin, rolipram, and thalidomide to decrease in vitro production of TNF- $\alpha$ and IFN- $\gamma$ in cells of HTLV1-infected subjects. Participants of the study included 19 patients with HAM/TSP (mean age, $53 \pm 11$; male:female ratio, 1:1) and 18 HTLV-1 carriers (mean age, $47 \pm 11$; male:female ratio, 1:2.6). Cytokines were determined by ELISA in supernatants of mononuclear cell cultures. Pentoxifylline inhibited TNF- $\alpha$ and IFN- $\gamma$ synthesis with the minimum dose used (50 $\mu M)$. The results with forskolin were similar to those observed with pentoxifylline. The doses of rolipram used were $0.01-1 \mu \mathrm{M}$ and the best inhibition of TNF- $\alpha$ production was achieved with $1 \mu \mathrm{M}$ and for IFN- $\gamma$ production it was $0.01 \mu \mathrm{M}$. The minimum dose of thalidomide used $(1 \mu \mathrm{M})$ inhibited TNF- $\alpha$ production but thalidomide did not inhibit IFN- $\gamma$ production even when the maximum dose $(50 \mu \mathrm{M})$ was used. All drugs had an in vitro inhibitory effect on TNF- $\alpha$ production and, with the exception of thalidomide, all of them also decreased IFN-Y production.
\end{abstract}

Key words: HTLV-1; TNF-a inhibitors; Pentoxifylline; Immune response

\section{Introduction}

Human lymphotropic virus type 1 (HTLV-1) infection is endemic in Brazil (1) and the city of Salvador has the highest prevalence among blood donors $(1.35 \%)$ and in the population $(1.76 \%)(2,3)$. HTLV-1 is the causal agent of adult T-cell leukemia-lymphoma (ATL), and of a chronic inflammatory disease of the central nervous system (HTLV-1 associated myelopathy/tropical spastic paraparesis, HAM/ TSP) (4). HTLV-1 infection induces T-cell activation and in vitro spontaneous lymphocyte proliferation leading to the production of high levels of interferon- $\mathrm{Y}$ (IFN- $\mathrm{\gamma}$ ) and tumor necrosis factor- $\alpha$ (TNF- $\alpha$ ) in non-stimulated peripheral blood mononuclear cells (PBMC) (5,6). HAM/TSP is characterized by progressive spastic paraparesis and occurs in less than $5 \%$ of HTLV-1-infected patients (7). High proviral load $(8,9)$ and increased expression of the pro-inflammatory cytokines TNF- $\alpha$ and IFN- $\gamma$ in PBMC as well as interleukin-1 (IL-1) and IL-6 in the cerebrospinal fluid (CSF) are associated with this disease $(4,10)$. Although these cytokines are more pronounced in HAM/TSP patients, evidence of enhanced T-cell activation is also detected in HTLV-1 carriers (11). Moreover, a large proportion of HTLV-I carriers, although they do not fulfill the criteria for HAM/TSP, have neurologi-

Correspondence: E.M. Carvalho, Serviço de Imunologia, Hospital Universitário Professor Edgard Santos, Rua João das Botas, s/n, 5o andar, 40110-160 Salvador, BA, Brasil. Fax: +55-71-3245-7110. E-mail: edgar@ufba.br and imuno@ufba.br

Received October 6, 2010. Accepted September 29, 2011. Available online October 21, 2011. Published November $14,2011$. 
cal symptoms such as erectile dysfunction and neurogenic bladder, features that may precede the development of $\operatorname{HAM} / T S P(12,13)$.

Due to the role of pro-inflammatory mediators in the pathogenesis of tissue damage associated with HTLV-1 infections, immunomodulatory agents are natural candidates to be used as adjuvant therapy in patients with HAM/TSP and in individuals who are at higher risk to develop myelopathy. Neutralization of TNF- $\alpha$ has been the most successful form of immunotherapy among the cytokine antagonists used in clinical practice (14-17). Inhibition of TNF- $\alpha$ synthesis can be achieved by several means: inhibition of transcription, decrease of mRNA half-life, and inhibition of translation (18). Although some substances act on more than one level, there are at least preferential modes of action. Pentoxifylline increases cAMP, blocks the transcription of TNF- $\alpha$ mRNA from macrophages (14) and down-regulates in vivo and in vitro the expression of intracellular adhesion molecule-1 (ICAM-1) in monocytes (19). Rolipram acts by blocking the transcription of TNF- $\alpha$ mRNA from macrophages; however, compared to pentoxifylline, it is more potent in suppressing TNF- $\alpha$ production from PBMC of patients with HAM/TSP (20). Thalidomide decreases the half-life of TNF- $\alpha$ mRNA $(14,15,21)$. The role of TNF- $\alpha$ in the inflammatory process has been documented in several inflammatory and infectious diseases such as multiple sclerosis, inflammatory bowel diseases, rheumatoid arthritis, and mucosal leishmaniasis $(14,16,17)$. The purpose of the present study was to evaluate the ability of TNF- $\alpha$ production inhibitors to decrease the in vitro production of pro-inflammatory cytokines such as IFN- $\gamma$ and TNF- $\alpha$. The overall data showed that all drugs had an inhibitory effect on TNF- $\alpha$ production and, with the exception of thalidomide, all of them also decreased IFN-Y production.

\section{Material and Methods}

\section{Study design and patient selection}

This was an experimental in vitro study evaluating the effect of four TNF- $\alpha$ inhibitors, i.e., pentoxifylline, forskolin, rolipram, and thalidomide, in PBMC of individuals infected with HTLV-1. Samples were taken under informed consent, and the study was conducted with the approval of the Ethics Committee of Hospital Universitário Professor Edgard Santos. The study subjects consisted of 37 patients who attended the HTLV-1 clinic of Hospital Universitário Professor Edgard Santos, Universidade Federal da Bahia, Brazil. All patients were evaluated by a neurologist. Motor and other neurological dysfunctions were measured with two scales: Expanded Disability Status Scale (EDSS) (22) and Osame's Motor Disability Score (OMDS). Exclusion criteria were positive serology for HIV-1 and -2, syphilis, and hepatitis virus B or C infection. Seven HTLV-1-negative individuals participated as controls. Nineteen $(53 \pm 11$ years old) of the 37 HTLV-1-positive subjects had HAM/TSP defined by neurological abnormalities (OMDS $\geq 1$ EDSS $\geq 2$ ) and the presence of anti-HTLV-1 antibody in CSF. The other 18 individuals ( $47 \pm 11$ years old) were HTLV- 1 carriers and had OMDS $=0$ and EDSS $\leq 2$. The diagnosis of HTLV-1 infection was based on a positive serology by ELISA(Murex HTLV-I + II, England), confirmed by Western blot analysis (Genelabs HTLV 2.3-2.4, Singapore).

\section{PBMC cultures and in vitro assays of drug effects}

PBMC from HTLV-1-infected individuals and controls were isolated from heparinized blood by density gradient centrifugation with Ficoll-Hypaque as described (6). Briefly, PBMC were washed with saline and $3 \times 10^{6}$ cells $/ \mathrm{mL}$ per well were cultured on 24-well flat-bottom plates (Falcon, Becton Dickinson, USA), in RPMI 1640 (Life Technologies Gibco BRL, USA), supplemented with $10 \%$ human $A B$ serum (Sigma, USA), glutamine, HEPES, and antibiotics. The cultures were kept without a stimulus for $72 \mathrm{~h}$ at $37^{\circ} \mathrm{C}, 5 \% \mathrm{CO}_{2}$ in the absence or presence of the TNF- $\alpha$ inhibitors. TNF- $\alpha$ and IFN- $y$ levels were measured in cell supernatants by the ELISA sandwich technique according to manufacturer instructions (PharMingen, USA). The activity of TNF- $\alpha$ inhibitors and cell viability were tested by evaluating the best dose able to inhibit TNF- $\alpha$ and IFN-Y while maintaining cell viability. Dose-response curves were constructed using non-stimulated PBMC from HAM/TSP patients and $\mathrm{PBMC}$ from healthy controls stimulated with phytohemagglutinin (PHA) at a final dilution of 1:10. The concentrations of the drugs tested were: 1, 10, 50, and 200 $\mu \mathrm{M}$ for pentoxifylline, forskolin, and thalidomide, and 0.01 , $0.1,1,10,100 \mu \mathrm{M}$ for rolipram. Cell viability was measured by counting the number of live cells stained with Trypan blue after 72-h incubation with the drugs tested. The results are reported as $\mathrm{pg} / \mathrm{mL}$ by interpolation in a standard curve with the recombinant cytokines.

\section{Semi-quantitative reverse transcriptase-polymerase chain reaction (RT-PCR) to detect IFN-Y}

Total RNA was isolated from PBMC of $4 \mathrm{HAM} / \mathrm{TSP}$ and 8 HTLV-1 carriers with and without pentoxifylline (50 $\mu M)$. The RNA was extracted from PBMC using Trizol LS reagent (Invitrogen, USA). cDNA was synthesized using 3 mg total RNA and reverse-transcribed by M-MLV reverse transcriptase. PCR was then performed in a final volume

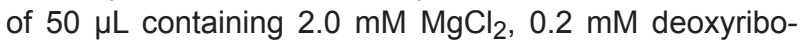
nucleoside triphosphate (dNTP) mix (dATP, dCTP, dTTP, dGTP), 10X PCR buffer, 2.5 U Taq DNA polymerase recombinant (Invitrogen), and specific primers at 25-50 pmol using a Veriti Thermal Cycler (Applied Biosystems, USA). The human primer sequences were: HPRT forward: GCGTCGTGATTAGTGATGATGAAC and HPRT reverse: GGATTATACTGCCTGACCAAGG; IFN-y forward: CAGCTCTGCATCGTTTTGGGTTCT and IFN-y reverse: TGCTCTTCGACCTCGAAACAGCAT. The PCR profiles used were: 30 cycles of $1 \mathrm{~min}$ at $95^{\circ} \mathrm{C}$ for denaturation, $1 \mathrm{~min}$ 
at $60^{\circ} \mathrm{C}$ for annealing and extension for 1 $\min 30 \mathrm{~s}$ at $72^{\circ} \mathrm{C}$, plus a final extension step of 10 min at $72^{\circ} \mathrm{C}$. The PCR amplification products were visualized on $1.3 \%$ agarose gel stained with $0.2 \%$ ethidium bromide (Sigma). Band intensity was calculated using the Vision Works LS image acquisition system version 6.5.2 (UVP, UK). Results are reported as relative units (RU) corrected for HPRT expression.

\section{Statistical analysis}

The nonparametric Mann-Whitney U-test was used to compare data between patients with HAM/TSP and HTLV-1 carriers. The nonparametric paired Wilcoxon signed rank test was used to compare the cytokine levels in PBMC culture supernatants without and with the drugs tested. These tests were performed using the Instat program (USA), and $P$ values $<0.05$ were considered to be of statistical significance.

\section{Results}

\section{Study subjects and IFN-Y and TNF- $\alpha$ levels}

The degree of neurological dysfunction and the concentrations of TNF- $\alpha$ and IFN-y in 19 patients with HAM/TSP and $18 \mathrm{HTLV}-1$ carriers are shown is Table 1 . There was no difference in age between the two groups. As expected, EDSS and OMDS scores were higher in patients with HAM/ TSP than in HTLV-1 carriers. There was wide variability in the levels of both cytokines. The median IFN- $y$ level was 291 $\mathrm{pg} / \mathrm{mL}$, with values ranging from 0 to $1,877 \mathrm{pg} / \mathrm{mL}$, in HAM/ TSP patients, and $11 \mathrm{pg} / \mathrm{mL}$, with values ranging from 0 to $1,950 \mathrm{pg} / \mathrm{mL}$, in HTLV-1 carriers $(P=0.017)$. The median level of TNF- $\alpha$ was $148 \mathrm{pg} / \mathrm{mL}$ in HAM/TSP patients, ranging from 0 to $1,334 \mathrm{pg} / \mathrm{mL}$, and $5 \mathrm{pg} / \mathrm{mL}$ in HTLV-1 carriers, with values ranging from 0 to $926 \mathrm{pg} / \mathrm{mL}(P=0.013)$.

\section{Effect of TNF- $\alpha$ inhibitors}

The effect of TNF- $\alpha$ inhibitors was determined in all infected subjects, independent of group, who had spontaneous TNF- $\alpha$ and IFN-y production $>50 \mathrm{pg} / \mathrm{mL}$. Since IFN- $\gamma$ levels were higher than TNF- $\alpha$ levels in HTLV-1 infection, there were more patients in the experiments evaluating IFN-y inhibition $(\mathrm{N}=16)$ than TNF- $\alpha$ inhibition $(\mathrm{N}=9)$. For each drug in culture the minimum and maximum doses able to suppress TNF- $\alpha$ and IFN- $\gamma$ in PHA-stimulated cultures and to maintain cell viability were used. Since rolipram was the least used of the three drugs tested, three concentrations of rolipram were used. Percent TNF- $\alpha$ and IFN- $y$ inhibition by pentoxifylline is shown in Table 1 and the concentrations of these cytokines observed in cultures without and with TNF- $\alpha$ inhibitors are shown in Figures 1, 2, and 3. The percentage

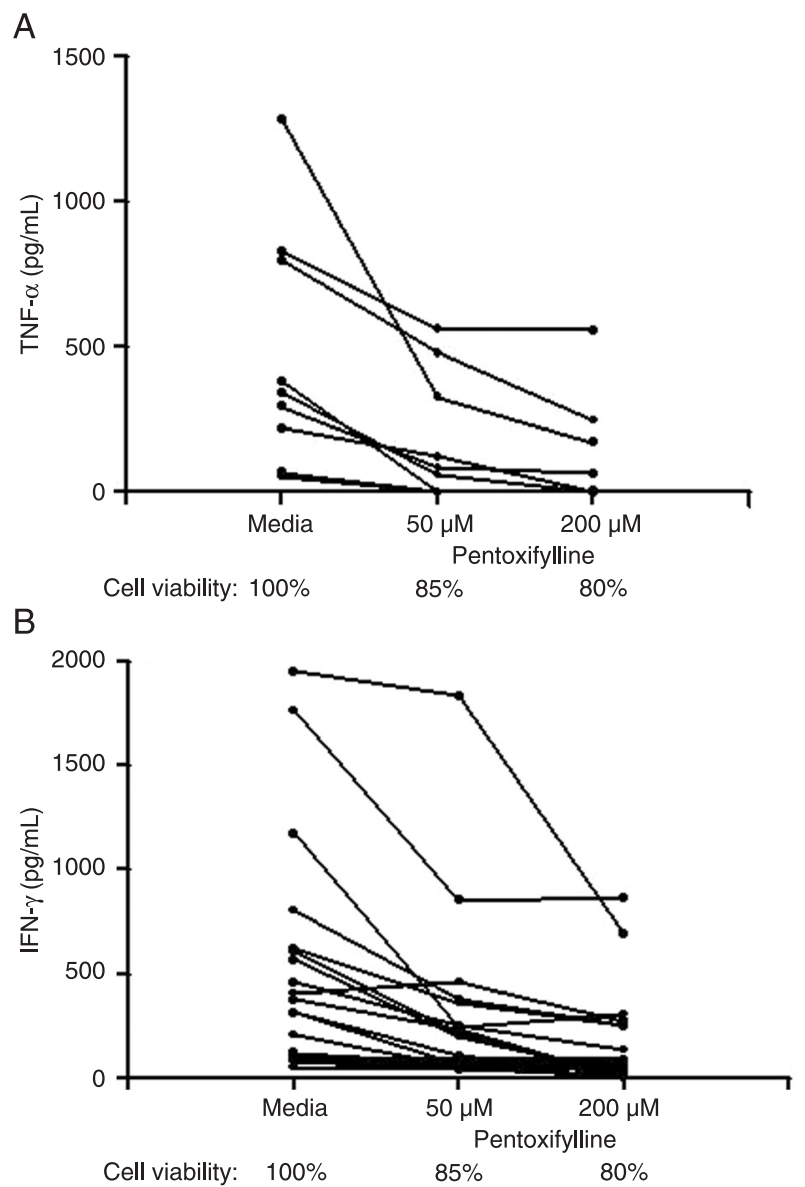

Figure 1. Effect of pentoxifylline on TNF- $\alpha$ and IFN- $\gamma$ levels. PBMC from HTLV-1-infected individuals ( $N=9$ and $N=5$ ) were exposed to 50 and $200 \mu \mathrm{M}$ pentoxifylline and the levels of TNF- $\alpha$ $(A)$ and IFN-Y $(B)$ were measured by ELISA. Cell viability was tested by counting the live and dead cells stained with Trypan blue after incubation with the drugs tested. TNF- $\alpha=$ tumor necrosis factor- $\alpha$; IFN- $\gamma=$ interferon- $\gamma$; PBMC = peripheral blood mononuclear cells; HTLV-1 = human T Iymphotropic virus type 1. 

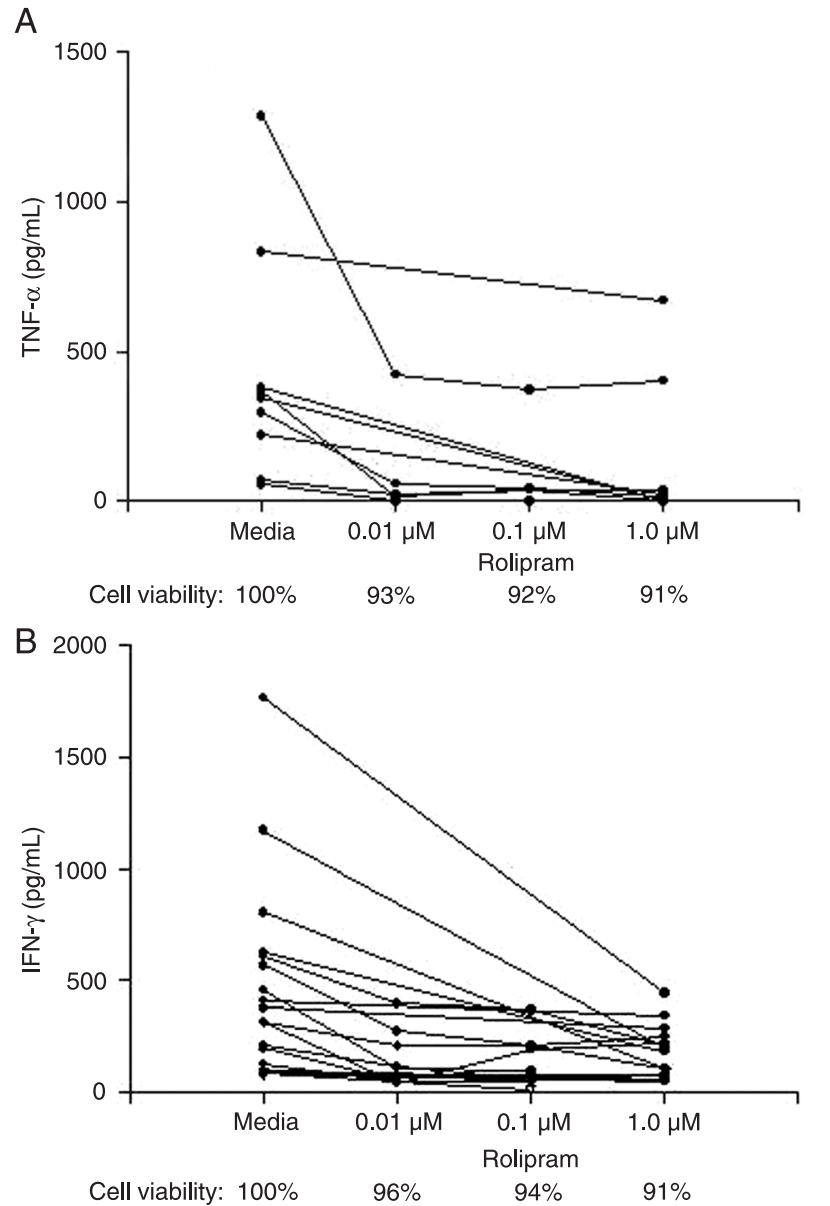

Figure 2. Effect of rolipram on TNF- $\alpha$ and IFN- $\gamma$ levels. PBMC from HTLV-1-infected individuals $(\mathrm{N}=8$ and $\mathrm{N}=10$ ) were exposed to $0.01 \mu \mathrm{M}, 0.1 \mu \mathrm{M}$, and $1.0 \mu \mathrm{M}$ rolipram and the levels of TNF- $\alpha(A)$ and IFN- $\gamma(B)$ were measured by ELISA. Cell viability was tested by counting the live and dead cells stained with Trypan blue after incubation with the drugs tested. For abbreviations, see legend to Figure 1.

of TNF- $\alpha$ inhibitor represents the data observed with the total number of individuals including HTLV-1 carriers and patients with HAM/TSP because the inhibition observed in these two groups was similar. For instance, the mean TNF- $\alpha$ inhibition with $50 \mu \mathrm{M}$ pentoxifylline in cells from the total group of 9 HTLV-1-positive subjects was $71 \pm 26 \%$, being $72 \pm 28 \%$ in $6 \mathrm{HAM} / \mathrm{TSP}$ patients and $70 \pm 30 \%$ in $3 \mathrm{HTLV}-1$ carriers $(\mathrm{P}=$ 0.92). At a concentration of $200 \mu \mathrm{M}$, the inhibition of TNF- $\alpha$ observed in cell cultures of HTLV-1-positive subjects was 84 $\pm 25-86 \pm 27 \%$ in the HAM/TSP group and $82 \pm 16 \%$ in the HTLV-1 carriers $(P=0.85)$. Pentoxifylline also decreases IFN-y synthesis. The inhibition of IFN-y production was 46 $\pm 24 \%$ with $50 \mu \mathrm{M}$ pentoxifylline and $65 \pm 29 \%$ with 200 $\mu \mathrm{M}$. As shown in Figure $1 \mathrm{~A}$ and $\mathrm{B}$, cell viability at the highest concentration of the drug was $80 \%$. The results with forskolin were similar to those observed with pentoxifylline.

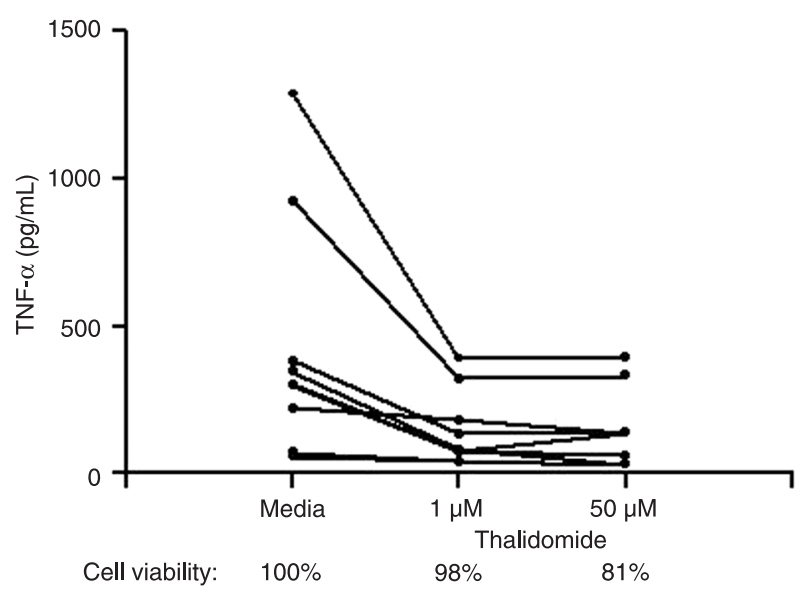

Figure 3. Effect of 1 and $50 \mu \mathrm{M}$ thalidomide on TNF- $\alpha$ levels of PBMC from HTLV-1-infected individuals $(N=8)$. The levels of TNF- $\alpha$ were measured by ELISA. Cell viability was tested by counting the live and dead cells stained with Trypan blue after incubation with the drugs tested. For abbreviations, see legend to Figure 1.

The inhibition of TNF- $\alpha$ production was $77 \pm 25 \%$ with 50 $\mu \mathrm{M}$ forskolin and $73 \pm 29 \%$ with $200 \mu \mathrm{M}$. The inhibition of IFN-y synthesis was $61 \pm 22$ and $77 \pm 25 \%$, respectively. The cell viability at the highest concentration of the drug was $79 \%$. The doses of rolipram used were $0.01,0.1$, and $1 \mu \mathrm{M}$. The best inhibition of TNF- $\alpha$ production was achieved with $1 \mu \mathrm{M}$, which caused $80 \pm 22 \%$ inhibition (Figure $2 \mathrm{~A}$ ). The minimum dose of rolipram $(0.01 \mu \mathrm{M})$ inhibited IFN-Y production by $47 \pm 20 \%$ while the maximum dose $(1.0 \mu \mathrm{M})$ inhibited it by $50 \pm 24 \%$ (Figure $2 B$ ). The cell viability with 1 $\mu \mathrm{M}$ rolipram was $91 \%$. The minimum dose of thalidomide used $(1 \mu \mathrm{M})$ was able to inhibit TNF- $\alpha$ production by $65 \pm$ $22 \%$ (Figure 3). Moreover, IFN-y levels after the addition of thalidomide were assayed only in five experiments because thalidomide showed no inhibitory effect on IFN-y (less than $50 \%$ inhibition) when the maximum dose $(50 \mu \mathrm{M})$ was used. These results show that pentoxifylline, forskolin and rolipram were able to suppress in vitro TNF- $\alpha$ and IFN-y production. It was also observed that thalidomide was efficient only in suppressing TNF- $\alpha$ synthesis.

\section{Detection of IFN-y mRNA by RT-PCR}

Since the ability of these drugs to decrease IFN-Y production represents new information, we evaluated whether pentoxifylline inhibited TNF- $\alpha$ RNA at the molecular level.

PBMC from HTLV-1-infected patients were cultured with and without $50 \mu \mathrm{M}$ pentoxifylline. After $72 \mathrm{~h}$ of culture the cells were harvested and IFN-y mRNA expression was analyzed by RT-PCR. IFN-y mRNA expression was detected in all cultures (with and without $50 \mu \mathrm{M}$ pentoxifylline) and no difference was observed between the HTLV-1-infected groups (data not shown). 


\section{Discussion}

HAM/TSP is a chronic immune-mediated neurologic disease characterized by leg weakness and spastic paraparesis that leads to physical disability $(23,24)$. TNF-a plays an important role in the pathogenesis of chronic inflammatory diseases (18). In HAM/TSP, IFN- $\gamma$ and TNF- $\alpha$ may contribute to tissue damage by recruiting inflammatory cells and inducing apoptosis. Moreover, these cytokines are also increased in serum and CSF and also stimulate nitric oxide (NO) and metalloproteinase synthesis (18). We show here that several drugs known to decrease TNF- $\alpha$ synthesis inhibit not only TNF- $\alpha$ but also IFN- $\gamma$ production in vitro by PBMC of both HTLV-1 carriers and HAM/TSP patients.

In the present study, we compared the action of TNF- $\alpha$ inhibitors on spontaneous TNF- $\alpha$ and IFN- $\gamma$ production by PBMC of HTLV-1-infected individuals to evaluate the effective dose needed to suppress the production of these cytokines and to maintain cell viability. These in vitro tests are important due to the wide variability in the activation state or deregulation of the immune system during HTLV-1 infection, which may influence the effects of drugs, including enhancement of cellular toxicity. Our in vitro results show that rolipram suppresses both TNF- $\alpha$ and IFN-y production by cell cultures from HTLV-1-infected subjects even at very low concentrations.

Pentoxifylline has been extensively studied in terms of TNF-suppressing activity (25). Pentoxifylline has been effective in the treatment of erythema nodosum in leprosy $(26,27)$ and, in combination with antimony therapy, it accelerates the healing time of cutaneous and mucosal leishmaniasis and the cure of patients refractory to antimony therapy $(16,28-30)$. Our results show that pentoxifylline had a good suppressor effect on the spontaneous production of TNF- $\alpha$, preserving cell viability. Additionally, it also decreased IFN-Y production to a lesser extent. Forskolin had an effect similar to that of pentoxifylline; however, it was more efficient in inhibiting IFN-y than pentoxifylline. Thalidomide analogues have been considered to have a high therapeutic potential for TNF- $\alpha$ inhibition by increasing the degradation of TNF- $\alpha$ mRNA in macrophages (15). Our results showed that thalidomide inhibited TNF- $\alpha$ production by PBMC at a low dose $(1 \mu \mathrm{M})$. However, it did not inhibit IFN-y production. The specificity of thalidomide in inhibiting only TNF- $\alpha$, preserving the production of IFN- $y$, can be important in situations where it is necessary to preserve the effector functions of this cytokine such as tumor cytotoxicity and antiviral activities, avoiding the induction of immunosuppression and predisposing to infections by intracellular agents and tumor development. Although IFN-Y production in HTLV-1 infection can be decreased by these drugs, the molecular mechanisms leading to the suppression of this cytokine are still not fully understood. Here we showed that IFN-y mRNA expression was not altered by pentoxifylline, indicating that in such case the inhibition is post-transcriptional, either regarding protein synthesis or protein secretion.

The drugs tested in the present study showed a high inhibitory effect on TNF-a production in vitro and, to a lesser extent, on IFN-y production by PBMC from HTLV-1-infected patients. IFN- $\gamma$ and TNF- $\alpha$ levels are very high in HTLV-1 infection and a possible role of these cytokines in both defense mechanisms but also in pathology associated with infection have been considered. IFN-y activates cytotoxic $T$ cells and stimulates TNF- $\alpha$ secretion and could induce neuronal destruction mediated by HTLV-1-specific cytotoxic CD8 $T$ cells and the production of mediators such as NO and metalloproteinases.

There is no effective therapy for HTLV-1. Anti-retroviral agents used for HIV associated with other drugs have improved the prognosis of ATL, but little effect has been shown on HAM/TSP (31). The pathogenesis of HAM/TSP is dependent on an exacerbated immunological response induced by the Tax gene of HTLV-1. However, although a large proportion of HTLV-1 carriers produce high levels of IFN- $\gamma$ and TNF- $\alpha$, they do not develop the disease $(6,32)$. We have observed that, in contrast to cells from patients with HAM/TSP, PBMC from HTLV-1 carriers can be downmodulated in vitro by regulatory cytokines such as IL-10 and TGF- $\beta$ and neutralizing antibodies against IL-2 and IL-15 (33). Other investigators have also shown a decrease in the frequency of regulatory T cells in patients with HAM/ TSP (34). These observations suggest that drugs having as target the inhibition of IFN- $\gamma$ and TNF- $\alpha$ production are potential agents to be used in HAM/TSP.

Anti-TNF- $\alpha$ therapy has been effective in other chronic disorders associated with high TNF- $\alpha$ levels such as rheumatoid arthritis, Crohn's disease, multiple sclerosis, leprosy, and mucosal leishmaniasis $(16,17,25,35,36)$. In HAM/TSP, open studies have also shown a beneficial effect of pentoxifylline $(37,38)$.

Pentoxifylline, rolipram, foskolin, and thalidomide inhibited TNF- $\alpha$ production in vitro in patients infected with HTLV-1. As down-modulation of the inflammatory response is desirable to prevent neurological damage in HTLV-1 infection, this study gives support to the use of this type of drug alone or in combination with antiretroviral therapy in the treatment of HTLV-1-infected subjects at high risk to develop HAM/TSP.

\section{Acknowledgments}

We thank the members of STS (Serviço de Transfusão de Sangue, Salvador, BA) and HEMOBA (Hemocentro da Bahia) for referring blood donors with HTLV-positive serology. We also thank Elbe Myrtes Souza Silva for technical assistance in preparing this manuscript. Research supported by $\mathrm{CNPq}$ and Fundação de Amparo à Pesquisa do Estado da Bahia (FAPESB). Dr. Edgar M. Carvalho is the recipient of a Research Productivity Grant $1 \mathrm{~A}$ from CNPq. 


\section{References}

1. Moreira ED Jr, Ribeiro TT, Swanson P, Sampaio Filho C, Melo A, Brites C, et al. Seroepidemiology of human T-cell lymphotropic virus type $1 / 1 \mathrm{I}$ in northeastern Brazil. J Acquir Immune Defic Syndr 1993; 6: 959-963.

2. Dourado I, Alcantara LC, Barreto ML, da Gloria TM, GalvaoCastro B. HTLV-I in the general population of Salvador, Brazil: a city with African ethnic and sociodemographic characteristics. J Acquir Immune Defic Syndr 2003; 34: 527531.

3. Galvao-Castro B, Loures L, Rodriques LG, Sereno A, Ferreira Junior OC, Franco LG, et al. Distribution of human Tlymphotropic virus type I among blood donors: a nationwide Brazilian study. Transfusion 1997; 37: 242-243.

4. Kubota R, Kawanishi T, Matsubara H, Manns A, Jacobson S. Demonstration of human T lymphotropic virus type I (HTLV-I) tax-specific CD8+ lymphocytes directly in peripheral blood of HTLV-I-associated myelopathy/tropical spastic paraparesis patients by intracellular cytokine detection. J Immunol 1998; 161: 482-488.

5. Ijichi S, Eiraku N, Osame M, Izumo S, Kubota R, Maruyama I, et al. In vitro modulation of lymphocyte proliferation by prednisolone and interferon-alpha in patients with HTLV-Iassociated myelopathy (HAM). J Neuroimmunol 1989; 23: 175-178.

6. Santos SB, Porto AF, Muniz AL, de Jesus AR, Magalhaes E, Melo A, et al. Exacerbated inflammatory cellular immune response characteristics of HAM/TSP is observed in a large proportion of HTLV-I asymptomatic carriers. BMC Infect Dis 2004; $4: 7$

7. Osame M. Pathological mechanisms of human T-cell lymphotropic virus type l-associated myelopathy (HAM/TSP). $J$ Neurovirol 2002; 8: 359-364

8. Kira J, Koyanagi Y, Yamada T, Itoyama Y, Goto I, Yamamoto $\mathrm{N}$, et al. Increased HTLV-I proviral DNA in HTLV-I-associated myelopathy: a quantitative polymerase chain reaction study. Ann Neurol 1991; 29: 194-201.

9. Nagai M, Usuku K, Matsumoto W, Kodama D, Takenouchi $\mathrm{N}$, Moritoyo T, et al. Analysis of HTLV-I proviral load in 202 HAM/TSP patients and 243 asymptomatic HTLV-I carriers: high proviral load strongly predisposes to HAM/TSP. J Neurovirol 1998; 4: 586-593.

10. Nishimoto N, Yoshizaki K, Eiraku N, Machigashira K, Tagoh $\mathrm{H}$, Ogata A, et al. Elevated levels of interleukin- 6 in serum and cerebrospinal fluid of HTLV-I-associated myelopathy/ tropical spastic paraparesis. J Neurol Sci 1990; 97: 183193.

11. Carvalho EM, Bacellar O, Porto AF, Braga S, GalvaoCastro B, Neva F. Cytokine profile and immunomodulation in asymptomatic human T-lymphotropic virus type 1-infected blood donors. J Acquir Immune Defic Syndr 2001; 27: 1-6.

12. Caskey MF, Morgan DJ, Porto AF, Giozza SP, Muniz AL, Orge GO, et al. Clinical manifestations associated with HTLV type I infection: a cross-sectional study. AIDS Res Hum Retroviruses 2007; 23: 365-371.

13. Castro N, Oliveira P, Freitas D, Rodrigues W, Muniz A, Carvalho $E$. Erectile dysfunction and HTLV-I infection: a silent problem. Int J Impot Res 2005; 17: 364-369.

14. Sandborn WJ, Targan SR. Biologic therapy of inflammatory bowel disease. Gastroenterology 2002; 122: 1592-1608.
15. Papadakis KA, Targan SR. Tumor necrosis factor: biology and therapeutic inhibitors. Gastroenterology 2000; 119: 1148-1157.

16. Lessa HA, Machado P, Lima F, Cruz AA, Bacellar O, Guerreiro J, et al. Successful treatment of refractory mucosal leishmaniasis with pentoxifylline plus antimony. Am J Trop Med Hyg 2001; 65: 87-89.

17. Sampaio EP, Hernandez MO, Carvalho DS, Sarno EN. Management of erythema nodosum leprosum by thalidomide: thalidomide analogues inhibit $M$. leprae-induced TNFalpha production in vitro. Biomed Pharmacother 2002; 56: 13-19.

18. Suryaprasad AG, Prindiville T. The biology of TNF blockade. Autoimmun Rev 2003; 2: 346-357.

19. Neuner P, Klosner G, Pourmojib M, Knobler R, Schwarz T. Pentoxifylline in vivo and in vitro down-regulates the expression of the intercellular adhesion molecule-1 in monocytes. Immunology 1997; 90: 435-439.

20. Hatae T, Hara H, Kobayashi T, Watanabe T. The effect of rolipram on the production of cytokines in HTLV-I infected cell lines and peripheral blood mononuclear cells of patients with HTLV-I-associated myelopathy (HAM). J Neurol Sci 1997; 148: 87-94

21. Marriott JB, Muller G, Dalgleish AG. Thalidomide as an emerging immunotherapeutic agent. Immunol Today 1999; 20: $538-540$

22. Kurtzke JF. Rating neurologic impairment in multiple sclerosis: an expanded disability status scale (EDSS). Neurology 1983; 33: 1444-1452.

23. Gessain A, Barin F, Vernant JC, Gout O, Maurs L, Calender A, et al. Antibodies to human T-lymphotropic virus type-I in patients with tropical spastic paraparesis. Lancet 1985; 2: 407-410.

24. Osame M, Usuku K, Izumo S, Ijichi N, Amitani H, Igata A, et al. HTLV-I associated myelopathy, a new clinical entity. Lancet 1986; 1: 1031-1032.

25. Eigler A, Sinha B, Hartmann G, Endres S. Taming TNF: strategies to restrain this proinflammatory cytokine. Immunol Today 1997; 18: 487-492.

26. de Carsalade GY, Achirafi A, Flageul B. [Pentoxifylline in the treatment of erythema nodosum leprosum: results of an open study]. Acta Leprol 2003; 12: 117-122.

27. Sampaio EP, Moraes MO, Nery JA, Santos AR, Matos HC, Sarno EN. Pentoxifylline decreases in vivo and in vitro tumour necrosis factor-alpha (TNF-alpha) production in lepromatous leprosy patients with erythema nodosum leprosum (ENL). Clin Exp Immunol 1998; 111: 300-308.

28. Machado PR, Lessa $H$, Lessa M, Guimaraes LH, Bang $H$, Ho JL, et al. Oral pentoxifylline combined with pentavalent antimony: a randomized trial for mucosal leishmaniasis. Clin Infect Dis 2007; 44: 788-793.

29. Ribeiro de Jesus A, Luna T, Pacheco de Almeida R, Machado PR, Carvalho EM. Pentoxifylline down modulate in vitro $\mathrm{T}$ cell responses and attenuate pathology in Leishmania and HTLV-I infections. Int Immunopharmacol 2008; 8: 13441353.

30. Sadeghian G, Nilforoushzadeh MA. Effect of combination therapy with systemic glucantime and pentoxifylline in the treatment of cutaneous leishmaniasis. Int J Dermatol 2006; 45: 819-821. 
31. Hermine $\mathrm{O}$, Dombret $\mathrm{H}$, Poupon J, Arnulf $\mathrm{B}$, Lefrere $\mathrm{F}$, Rousselot $\mathrm{P}$, et al. Phase II trial of arsenic trioxide and alpha interferon in patients with relapsed/refractory adult T-cell leukemia/lymphoma. Hematol J 2004; 5: 130-134.

32. Jacobson S. Immunopathogenesis of human T cell lymphotropic virus type I-associated neurologic disease. J Infect Dis 2002; 186 (Suppl 2): S187-S192.

33. Santos SB, Porto AF, Muniz AL, Luna T, Nascimento MC, Guerreiro JB, et al. Modulation of T cell responses in HTLV1 carriers and in patients with myelopathy associated with HTLV-1. Neuroimmunomodulation 2006; 13: 145-151.

34. Yamano Y, Takenouchi N, Li HC, Tomaru U, Yao K, Grant $\mathrm{CW}$, et al. Virus-induced dysfunction of CD4+CD25+ T cells in patients with HTLV-I-associated neuroimmunological disease. J Clin Invest 2005; 115: 1361-1368.

35. Krause I, Valesini G, Scrivo R, Shoenfeld Y. Autoimmune aspects of cytokine and anticytokine therapies. Am J Med 2003; 115: 390-397.

36. Rieckmann P, Weber F, Gunther A, Martin S, Bitsch A, Broocks A, et al. Pentoxifylline, a phosphodiesterase inhibitor, induces immune deviation in patients with multiple sclerosis. J Neuroimmunol 1996; 64: 193-200.

37. Shirabe S, Nakamura T, Tsujino A, Nishiura Y, Furuya T, Goto $\mathrm{H}$, et al. Successful application of pentoxifylline in the treatment of HTLV-I associated myelopathy. J Neurol Sci 1997; 151: 97-101.

38. Tsujino A, Nakamura T, Nishiura $Y$, Shirabe S, Furuya T, Goto $\mathrm{H}$, et al. Pentoxifylline down-regulates adhesion molecule expression and inflammatory cytokine production in cultured peripheral blood mononuclear cells from patients with HTLV-I-associated myelopathy. J Neuroimmunol 1997; 73: 191-196. 